\title{
lons Beam Properties Produced by NX2 Plasma Focus Device with Helium and Nitrogen Gas
}

\author{
Sahyouni Walid, Nassif Alaa \\ Plasma Physics Research Unit, Department of Physics, Faculty of Science, Al-Baath University, Homs, Syria \\ Email address: \\ wsahyouni@albaath-univ.edu.sy (S. Walid), anassif@albaath-univ.edu.sy (N. Alaa), alaa.nassif.85@hotmail.com (N. Alaa) \\ To cite this article: \\ Sahyouni Walid, Nassif Alaa. Ions Beam Properties Produced by NX2 Plasma Focus Device with Helium and Nitrogen Gas. American \\ Journal of Modern Physics. Vol. 8, No. 1, 2019, pp. 1-4. doi: 10.11648/j.ajmp.20190801.11
}

Received: March 21, 2019; Accepted: April 22, 2019; Published: May 9, 2019

\begin{abstract}
Numerical experiments carried out using the Lee code to study some properties of ions beam (flux, fluence and ion beam energy) produced by the NX2 dense plasma device when using light gas (helium) and heavy gas (nitrogen) when gas pressure changes. The results showed that in the case of light gas (helium), the flux and fluence of the beam were higher while the ion beam energy was higher in the case of heavy gas (nitrogen) because the effective charge of nitrogen's ion is greater and also the voltage generated by the collapse of pinch was higher.
\end{abstract}

Keywords: Dense Plasma Focus, Plasma Pinch, Lee Code

\section{Introduction}

Dense plasma focus plasma is one way to get a very hotvery dense plasma through an electric discharge within a gas confined in a device called the DPF device. For this purpose, high currents of the kilo amps are required to ionize the gas under certain pressure within the vacuum chamber containing a set of electrodes (cathode and anode).

When discharging, a plasma sheath is formed and moving from the anode towards the cathode. The Lorenz force generates push the plasma sheath axially along the electrodes. When it reaches its end, radial Lorenz's force push the plasma sheath to the top of the anode in the form of a small, very hot, very thin column called a pinch.

The first models of dense plasma devices were developed in the 1960s by Mather in USA [1] and Filippov in USSR [2]. These two models agree in terms of the principle of operation but differ in geometry (the characteristic ratio) where in the Filippov's model note the absence of the axial acceleration phase.

Due to the high density and temperature of the plasma pinch during its stagnation at the top of the anode, it is the source of a large number of radiation emissions (such as soft $\mathrm{x}$-ray SXR) and its collapse due to non-stabilities leads to the formation of voltage works to accelerate the electrons and ions in opposite directions.
The resulting ions beams have great energy that can be used in different applications such as manufacture thin films, semiconductors and the production short-lived radioisotopes (SLR)....etc. Therefore it is important to study the properties of ions beam for their suitability for different applications. In this paper we studied the changes in some of the characteristics of the ions beam (flux, fluence and ion beam energy) when gas pressure was changed using the Lee code.

\section{Lee's Code}

Lee's code is one of the most important codes used to simulate the plasma focus phenomenon. This code links the electrical circuit parameters with the kinetics, thermodynamics and radiation emissions of the plasma focus in advance to a realistic simulation of all the characteristics of the plasma focus. It was first developed in 1985 and was a two-stage program that was used to describe and improve plasma focus devices [3] and was later developed into five phases [4]. This version was published in 2000 [5], and the effect of plasma self-absorption was included in 2007 [4]. This code was used as a complement to the study of UNU / ICTP PFF [6], NX1 [7], NX2 [8] and DENA [9], a modified model of the Filippov model. The program has also been used to improve many lowenergy devices such as FNII [10], UBA [11] and KSU PF [12].

The information calculated by this code includes the dynamics of the axial and radial phases, the advantages and 
the yield of the SXR using different gases, and the neutron yield and improvement of this yield at different gas pressure values and the capacity of the capacitor bank. In addition, the code opens up broad prospects for conducting numerical experiments on plasma and using it as an advanced training system in nuclear fusion research [13].

\section{Properties of Ions Beam from the Plasma Focus}

Lee and Saw studied the properties of the ions beam from the collapse of the plasma pinch and concluded the relationship of flux, fluence, and ion beam energy as follows [14]:

Flux (ions. $\left.\mathrm{m}^{-2} \cdot \mathrm{s}^{-1}\right)$ :

$$
F L U X=2.75 \times 10^{15} \frac{f_{e}}{\sqrt{M . Z_{\text {eff }}}} \cdot \frac{\ln \left[b / r_{P}\right]}{r_{P}^{2}} \cdot \frac{I_{P i n c h}^{2}}{\sqrt{U}}
$$

Where:

$f_{e}=0.14$ : the fraction of energy converted from pinch inductive energy into beam kinetic energy, $M$ is the mass number of ion, $Z_{\text {eff }}$ the effective charge, $b$ is the cathode radius, $r_{p}$ pinch radius, $I_{\text {pinch }}$ pinch current, The diode voltage U.

Fluence (ions. $\mathrm{m}^{-2}$ ):

$$
\text { FLUENCE }=2.75 \times 10^{15} \frac{f_{e}}{\sqrt{M . Z_{\text {eff }}}} \cdot \frac{\ln \left[b / r_{P}\right]}{r_{P}^{2}} \cdot \frac{I_{\text {Pinch }}^{2}}{\sqrt{U}} \cdot \tau
$$

Where: $\tau$ pinch duration

Energy in beam (Joul):

$$
E=Z_{\text {eff. }} \cdot U \times \text { ionsnumber }
$$

\section{Results and Discussion}

Using Lee code, a series of numerical experiments carried out on the dense plasma focus device according to the following parameters:

i Capacitor bank parameters: $\mathrm{L}_{0}=20 \mathrm{nH}, \mathrm{C}_{0}=28 \mu \mathrm{F}, \mathrm{r}_{0}$ $=2.3 \mathrm{~m} \Omega$.

ii Parameters of the plasma tube: $\mathrm{b}=4.1 \mathrm{~cm}, \mathrm{a}=1.9 \mathrm{~cm}$, $\mathrm{z}_{0}=5 \mathrm{~cm}$.

iii Operating parameters: $\mathrm{V}_{0}=14 \mathrm{kV}$.

iv Parameters of the model: $f_{m}=0.08, f_{c}=0.7, f_{m r}=0.2$, $\mathrm{f}_{\mathrm{cr}}=0.7[15]$.

Ions flux with gas pressure changes:

The pressure of both helium and nitrogen gases was changed and the flux value of the outgoing ions bean was determined using the relation (1). The results were as

\begin{tabular}{|c|c|c|}
\hline Pressure Torr & $\begin{array}{l}\text { Helium Ions Flux } \\
\text { Ions. }^{-2} \cdot \mathrm{s}^{-1}\end{array}$ & 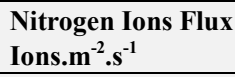 \\
\hline 1 & $3.20 \mathrm{E}+27$ & $3.03 \mathrm{E}+27$ \\
\hline 2 & $4.27 \mathrm{E}+27$ & $4.29 \mathrm{E}+27$ \\
\hline 3 & $4.98 \mathrm{E}+27$ & $4.98 \mathrm{E}+27$ \\
\hline 4 & $5.51 \mathrm{E}+27$ & $4.92 \mathrm{E}+27$ \\
\hline 5 & $5.91 \mathrm{E}+27$ & $4.60 \mathrm{E}+27$ \\
\hline 6 & $6.22 \mathrm{E}+27$ & $4.06 \mathrm{E}+27$ \\
\hline 7 & $6.46 \mathrm{E}+27$ & $3.32 \mathrm{E}+27$ \\
\hline 8 & $6.65 \mathrm{E}+27$ & $2.48 \mathrm{E}+27$ \\
\hline 9 & $6.79 \mathrm{E}+27$ & $1.72 \mathrm{E}+27$ \\
\hline 10 & $6.87 \mathrm{E}+27$ & $1.10 \mathrm{E}+27$ \\
\hline 11 & $6.93 \mathrm{E}+27$ & \\
\hline 12 & $6.94 \mathrm{E}+27$ & \\
\hline 13 & $6.93 E+27$ & \\
\hline 14 & $6.88 \mathrm{E}+27$ & \\
\hline 15 & $6.80 \mathrm{E}+27$ & \\
\hline 16 & $6.71 \mathrm{E}+27$ & \\
\hline 17 & $6.58 \mathrm{E}+27$ & \\
\hline 18 & $6.43 \mathrm{E}+27$ & \\
\hline 19 & $6.26 \mathrm{E}+27$ & \\
\hline
\end{tabular}
follows:

Table 1. Change the ions beam flux when the gas pressure changes

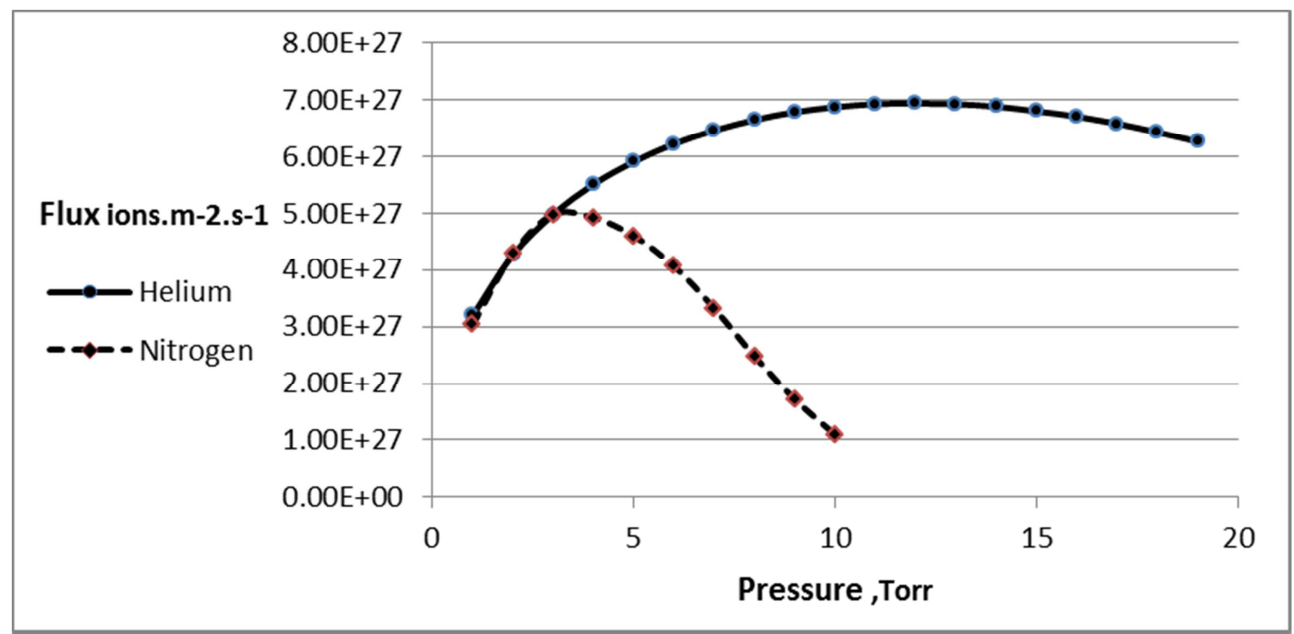

Figure 1. Change the ions beam flux when the gas pressure changes. 
Figure 1 shows that the flux curve of the helium ions is gradually increased with the gas pressure increasing to a maximum value of $6.94 \mathrm{E}+27$ at 12 Torr and then decreases slightly with continuous pressure increase. While the flux of the nitrogen ions increased with the gas pressure increasing to a maximum value of $4.98 \mathrm{E}+27$ at 3 Torr and then decreased sharply with continued pressure increase.

Noted that the flux value of helium ions is greater. This is because the radius of the pinch in helium is greater than in nitrogen, so the number of ions trapped within the pinch is greater.

Ions fluence with gas pressure changes:

Using the relation (2), the ions fluence value was calculated at each pressure value and the results were as shown in Table 2:

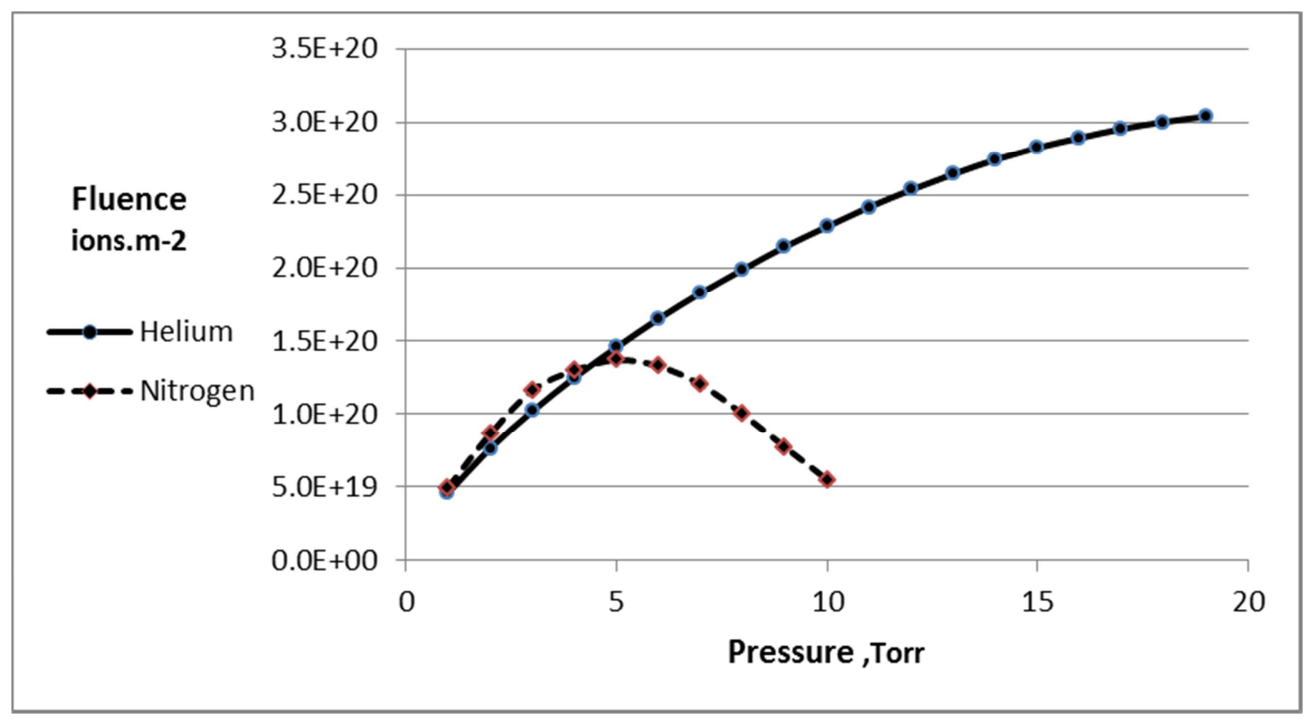

Figure 2. Change the ions beam fluence when the gas pressure changes.

Table 2. Change the ions beam fluence when the gas pressure changes

\begin{tabular}{lll}
\hline Pressure Torr & $\begin{array}{l}\text { Helium Ions Fluence } \\
\text { Ions.m } \text { - }^{-2}\end{array}$ & $\begin{array}{l}\text { Nitrogen Ions } \\
\text { Fluence Ions.m }\end{array}$ \\
\hline 1 & $4.6 \mathrm{E}+19$ & $4.90 \mathrm{E}+19$ \\
2 & $7.6 \mathrm{E}+19$ & $8.60 \mathrm{E}+19$ \\
3 & $1.0 \mathrm{E}+20$ & $1.20 \mathrm{E}+20$ \\
4 & $1.2 \mathrm{E}+20$ & $1.30 \mathrm{E}+20$ \\
5 & $1.5 \mathrm{E}+20$ & $1.40 \mathrm{E}+20$ \\
6 & $1.6 \mathrm{E}+20$ & $1.30 \mathrm{E}+20$ \\
7 & $1.8 \mathrm{E}+20$ & $1.20 \mathrm{E}+20$ \\
8 & $2.0 \mathrm{E}+20$ & $1.00 \mathrm{E}+20$ \\
9 & $2.1 \mathrm{E}+20$ & $7.70 \mathrm{E}+19$ \\
10 & $2.3 \mathrm{E}+20$ & $5.50 \mathrm{E}+19$ \\
11 & $2.4 \mathrm{E}+20$ & \\
12 & $2.5 \mathrm{E}+20$ & \\
13 & $2.6 \mathrm{E}+20$ & \\
14 & $2.7 \mathrm{E}+20$ & \\
15 & $2.8 \mathrm{E}+20$ & \\
16 & $2.9 \mathrm{E}+20$ & \\
17 & $3.0 \mathrm{E}+20$ & \\
18 & $3.0 \mathrm{E}+20$ & \\
19 & $3.0 \mathrm{E}+20$ & \\
\hline
\end{tabular}

Figure 2 shows the change in the fluence of the helium ions beam, where a gradual increase is observed with increasing gas pressure until a maximum value of $3.0 \mathrm{E}+20$ is reached at 19 Torr. The fluence of the nitrogen ions beam is increased with increasing gas pressure until reaching a maximum value of $1.4 \mathrm{E}+20$ at Torr 5 and then decreases sharply while the pressure continues to increase. Note that the helium ion fluence is greater and this is because the duration of the helium pinch is greater.

Change the beam energy with gas pressure change:

At each gas pressure value, the ion beam energy was calculated using the relation (3) and the results shown in Table 3:

Table 3. Change the energy of the ions beam when gas pressure changes

\begin{tabular}{lll}
\hline Pressure Torr & $\begin{array}{l}\text { Helium Beam Energy } \\
\text { Joul }\end{array}$ & $\begin{array}{l}\text { Nitrogen Beam } \\
\text { Energy Joul }\end{array}$ \\
\hline 1 & 43 & 121 \\
2 & 66 & 154 \\
3 & 83 & 173 \\
4 & 97 & 179 \\
5 & 108 & 179 \\
6 & 117 & 169 \\
7 & 125 & 157 \\
8 & 130 & 139 \\
9 & 136 & 118 \\
10 & 139 & 95 \\
11 & 142 & \\
12 & 144 & \\
13 & 146 & \\
14 & 147 & \\
15 & 147 & \\
16 & 146 & \\
17 & 145 & \\
18 & 144 & \\
19 & 142 & \\
\hline
\end{tabular}




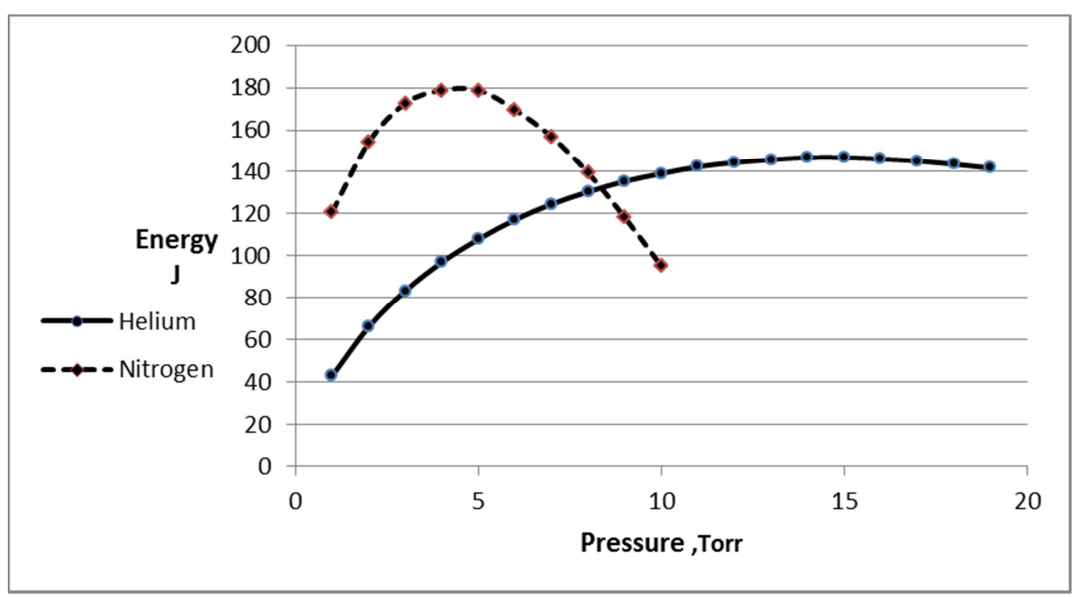

Figure 3. Change the energy of the ion beam when gas pressure changes.

Figure 3 shows that the energy of the ion beam increases with pressure increasing until it reaches a high value and then decreases as the pressure increases.

Observed that the energy of the nitrogen ions beam is higher than helium, although the flux of the helium ions is higher, due to the height of both the pinch's voltage and the number of effective charge in the case of nitrogen.

The percentage of the highest ion energy beam was calculated for the operating power of the device. This percentage was found in the case of helium gas $(5.44 \%)$ while in the case of nitrogen $(6.62 \%)$.

\section{Conclusions}

A series of numerical experiments carried out to calculate the flux, fluence and ion energy beam from the plasma pinch when the helium and nitrogen gas pressure changes from 1 Torr. The results showed that in the case of helium gas, the highest pressure value was 19 Torr and in the case of nitrogen gas was 10 Torr and no pressure value above these two values did not get focus because the movement of the plasma sheath in the axial and radial directions is very large compared to the time of discharge of the capacitor bank.

The result showed that each of these characteristics increases with increasing pressure until reaching a high value and then decreasing and continuing with increasing pressure. Although the flux and fluence of the helium ion beam was higher, the nitrogen beam energy is higher because the voltage generated by the collapse of the nitrogen plasma pinch and the effective charge of the nitrogen ion is higher than the helium ion.

\section{References}

[1] Mather, J. W. (1965). Formation of a high - density deuterium plasma focus. The Physics of Fluids, 8 (2), 366-377.

[2] Filippov, N. V., Filippova, T. I., \& Vinogradov, V. P. (1962). Dense high-temperature plasma in a non-cylindrical Z-pinch compression. Nucl. Fusion, Suppl.

[3] Lee. S, Tou. T. Y, Moo. S. P, Eissa. M. A, Gholap. A. V,
Kwek. K. H, Mulyodrono. S, Smith. A., Usala. S. W, Zakaullah. M. (1988). A simple facility for the teaching of plasma dynamics and plasma nuclear fusion. Am. J. Phys. 56, 62-68 doi: http://dx.doi.org/10.1119/1.15433

[4] Lee. S., Radiative dense plasma focus computation package: RADPF. http://www. plasmafocus.net/IPFS/modelpackage/File1RADPF.htm

[5] Lee. S. (2013). in http://ckplee.home.nie.edu.sg/plasmaphysics/ (archival website).

[6] Saw. S. H, Damideh. V, Lee. P. C. K, Rawat. R. S, Lee. S, Comparative study of fast and slow focus modes in INTI plasma focus for deuterium, neon and argon operation. (submitted for publication).

[7] Zhang. G. X. (1999). Plasma soft x-ray source for microelectronic lithography. PhD thesis. NTU, Singapore.

[8] Koh. J. M, Rawat. R. S, Patran. A, Zhang. T, Wong. D, Springham. S. V, Tan. T. L, Lee. S, Lee. P (2005). Optimization of the high pressure operation regime for enhanced neutron yield in a plasma focus device. Plasma Sour. Sci. Technol. 14, 12.

[9] V. Siahpoush, Tafreshi. M. A, Sobhanian. S, Khorram. S. (2005). Plasma Phys. Controlled Fusion 47, 1065.

[10] H. Acuna, F. Castillo, J. Herrera, A. Postal. (1996). Int. Conf. Plasma Sci. p. 127.

[11] Moreno. C, Raspa. V, Sigaut. L, Vieytes. (2006). R, Appl. Phys. Lett. 89.

[12] Abdou. A. E, Ismail M. I., Mohamed. A. E, Lee. S, Saw. S. H, Vermam R. (2012). Preliminary results of Kansas State University dense plasma focus. IEEE Trans. Plasma Sci. 40 (10), 2741-2744 doi: 10.1109/TPS.2012.2209682.

[13] Rawat, R. S. (2013). High-energy-density pinch plasma: A unique nonconventional tool for plasma nanotechnology. IEEE Transactions on Plasma Science, 41 (4), 701-715.

[14] Lee, S., \& Saw, S. H. (2013). Plasma focus ion beam fluence and flux-For various gases. PHYSICS OF PLASMAS 20, 062702 .

[15] Lee, S., \& Saw, S. H. (2013). Scaling of Ion Beams from Plasma Focus in Various Gases. INTI International University Nilai Malaysia, 14 June 2013. 